\title{
2-Tuple Linguistic Integrated Group Decision Making Methodology for E-Commerce Strategy Selection
}

\author{
Gülçin Büyüközkan ${ }^{a}$ and Deniz Uztürk $^{b}$ \\ ${ }^{a}$ Department of Industrial Engineering, Faculty of Engineering, Galatasaray University, Istanbul, Turkey, \\ gulcin.buyukozkan@gmail.com \\ bDepartment of Business Administration, Faculty of Economics and Administrative Sciences, Galatasaray \\ University, Istanbul, Turkey, uzturkdeniz@gmail.com
}

\begin{abstract}
2-Tuple linguistic model, which is a fuzzy logic based linguistic decision-making tool, enables the use of multi-granulated linguistic variables in decision making. This property facilitates the decision-making process for decision makers (DMs) and provides a comfortable decision-making environment for them. Motivated by this advantage, this study suggests a decisionmaking methodology for a strategy selection subject. E-commerce subject is selected as an application area because of its growth in every sector as a result of the rapidly expanding new technologies. In this study, integrated SWOT analysis with group decision making (GDM) considering linguistic information is proposed. 2-Tuple linguistic model is used to normalize and aggregate them. An SME in the textile sector from Turkey has been chosen as a case study to test the applicability. The most suitable strategy for the SME business is determined with 2-Tuple decision making by FLINTSTONES program.
\end{abstract}

Keywords: Group decision making, SWOT analysis, 2-Tuple linguistic model, Strategy selection, FLINTSTONES

\section{Introduction}

The procedure of buying and selling by electronic measures is the simple definition of e-commerce. It is a basic buying and selling process, but today it budges all the structures of business models. The traditional structure of the business is transformed into a new system where technology leads the strategical decisions [1].

The rapid growth in technology creates excellent opportunities for businesses, and it obliges the organizations to act agile to the changing environment [1]. The leading network that enables the e-commerce for organizations is the Internet which is a worldwide network built on the same standards. The massive growth in Internet helped e-commerce to develop.
Furthermore, the creation of mobile platforms augmented the availability and accessibility of the internet through small devices. The mobile platforms such as smartphones and tablets increased the ability to use e-commerce easily for consumers, and such simplicity earned significant growth to e-commerce [2].

As mentioned before, the business models change rapidly according to the environment which is profoundly affected by social and technological trends [3]. To comply with the changing environment, the organization should hold a compelling business strategy where it can examine the inner organizational structure and its outside environment.

Managing the investigation of inside and outside environment could be handled by a well-known technique called SWOT which consists of the initials of the words: strengths, weaknesses, opportunities, and threats respectively. Making evaluations with SWOT is a critical decision-making procedure which succeeds when it is performed with group decision making. Here are the studies conducted in the last five years about strategy selection with SWOT are given in Table 1 .

\begin{tabular}{|c|c|c|}
\hline Year & Subject & GDM \\
\hline $\begin{array}{l}2015 \\
{[4]}\end{array}$ & $\begin{array}{l}\text { MADM model via fuzzy } \\
\text { cognitive maps and hierarchical } \\
\text { fuzzy TOPSIS }\end{array}$ & $x$ \\
\hline $\begin{array}{l}2016 \\
{[5]}\end{array}$ & $\begin{array}{l}\text { Strategy selection for the } \\
\text { development of an exercise APP. }\end{array}$ & $x$ \\
\hline $\begin{array}{l}2016 \\
{[6]}\end{array}$ & $\begin{array}{l}\text { Sustainable manufacturing } \\
\text { strategy selection }\end{array}$ & $x$ \\
\hline $\begin{array}{l}2016 \\
{[7]}\end{array}$ & Strategy portfolio optimization & $x$ \\
\hline $\begin{array}{l}2017 \\
{[8]}\end{array}$ & $\begin{array}{l}\text { Hierarchical MADM model by } \\
\text { combining DEMATEL and } \\
\text { TOPSIS with type-2 fuzzy sets }\end{array}$ & $\nabla$ \\
\hline $\begin{array}{l}2018 \\
{[9]}\end{array}$ & $\begin{array}{l}\text { Business strategy selection with } \\
\text { SWOT-ANP and Fuzzy TOPSIS }\end{array}$ & $\square$ \\
\hline $\begin{array}{l}2018 \\
{[10]}\end{array}$ & $\begin{array}{l}\text { Competitive strategy selection in } \\
\text { the European banking sector }\end{array}$ & $x$ \\
\hline
\end{tabular}

Table 1: Studies in the last five years about strategy selection with SWOT 
Motivated by the power of SWOT with GDM, this study proposes an integrated SWOT with its 2-Tuple linguistic extension to generate alternative strategies for e-commerce. Later, a selection of strategies is suggested with the 2-Tuple decision making with a software called FLINTSTONES [11].

The remainder of this study is as follows: Section 2 gives the preliminaries about the 2-Tuple linguistic model and its relations for group decision making. Section 3 gives the details of the suggested strategy selection methodology. Section 4 presents the case study application for e-commerce SME from Turkey, and finally, Section 5 gives the conclusion and perspectives of the study.

\section{Preliminaries of 2-Tuple Linguistic Model}

2-Tuple linguistic model is first introduced by Herrera and Martinez in 2000s [12]. The primary motivation to generate a 2-Tuple approach for computing with words is to handle the multi-granular and nonhomogeneous data obtained from resources. Moreover, it proposes easy computational steps while translating the linguistic values into crisp numbers. Here the essential preliminaries are given for the 2Tuple linguistic model:

Let $S=\left\{S_{0}, \ldots, S_{g}\right\}$ be a linguistic term set, which is set composed of linguistic variables, and $\beta \epsilon[0, g]$ a value supporting the result of a symbolic aggregation operation. Then the 2-Tuple that expresses the equivalent information to $\beta$, which is a crisp number, is obtained with the following function[13]:

$$
\begin{gathered}
\Delta:[0, g] \rightarrow \quad \mathcal{S} \times[-0.5,0.5) \\
\Delta(\beta)= \begin{cases}S i & i=\operatorname{round}(\beta) \\
\alpha & \alpha \in[-0.5,0.5)\end{cases}
\end{gathered}
$$

Here $\beta$ value represents the linguistic variables as a crisp number to be able to make calculations.Also, $\operatorname{round}(\beta)$ refers to classical round operation.

Let $\delta=\left\{S_{0} \ldots, S g\right\}$ be a linguistic term set and $\left(s_{i}, \alpha\right) \epsilon$ $\bar{S}$ be a 2-Tuple linguistic value and the reciprocal function is defined as[14]:

$$
\begin{aligned}
& \Delta^{-1}: \quad \overline{\mathcal{S}} \rightarrow[0, g] \\
& \Delta^{-1}\left(s_{i}, \alpha\right)=i+\alpha=\beta
\end{aligned}
$$

Where $\beta$ is the equivalent numerical value which belongs to $[0, g]$. And this reciprocal function enables the translation between the 2-Tuple linguistic values and crips values.

The linguistic term set can be transformed into 2Tuple linguistic value by adding zero as in the following relation [14]:

$$
s_{i} \in S \Rightarrow\left(s_{i}, 0\right) \in \overline{\mathcal{S}}
$$

The comparison of linguistic information represented by 2-Tuples is carried out according to an ordinary lexicographic order. Let $\left(S_{i}, \alpha_{1}\right)$ and $\left(S_{j}, \alpha_{2}\right)$ be two linguistic 2-Tuples, each representing a linguistic assessment [14]:

$>$ If $i<j$ then $\left(S_{i}, \alpha_{1}\right)$ is smaller than $\left(S_{j}, \alpha_{2}\right)$.

$>$ If $i=j$ then

$>$ If $\alpha_{1}=\alpha_{2}$ then $\left(S_{i}, \alpha_{1}\right)$ and $\left(S_{j}, \alpha_{2}\right)$ represent the same information.

$>$ If $\alpha_{1}>\alpha_{2}$ then $\left(S_{i}, \alpha_{1}\right)$ is smaller than $\left(S_{j}, \alpha_{2}\right)$

$>$ If $\alpha_{1}<\alpha_{2}$ then $\left(S_{i}, \alpha_{1}\right)$ is bigger than $\left(S_{j}, \alpha_{2}\right)$

These fundamental properties of 2-Tuple linguistic model enable to apply basic operations in linguistic term sets thanks to the reciprocal function.

Furthermore, the ability to normalize and aggregate multi-granular data is another dominant characteristic for 2-Tuple model, and it is instrumental in group decision making. The definitions for aggregation and normalization process for GDM are given in the next section.

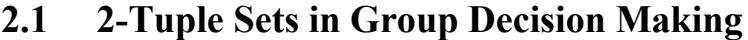

GDM is a participatory procedure where various individuals make evaluations, selections and decide about one subject [15]. In organizations, generally, many strategical decisions are made after a GDM process where the alternatives are assessed, and the solutions are discussed.

The 2-Tuple linguistic model enables the group members to express their opinion comfortably by proposing them linguistic scales compatible with their knowledge about the subject. Besides, it proposes multi preference expressions such as interval values, numerical values, and linguistic sets, to assess the subject. It enables to normalize non-homogeneous information to 2-Tuple form to be able to conduct calculations [14]. The necessary relations to handle multi-granular information are given as follows [14]:

Linguistic Hierarchies (LH) Approach for Multigranular data:

An LH is the union of all levels $t$ where each level $t$ corresponds to a linguistic term set symmetrically distributed with an odd granularity. The granularity of 
the linguistic term set refers to the number of variables minus one as the linguistic term set starts from zero.

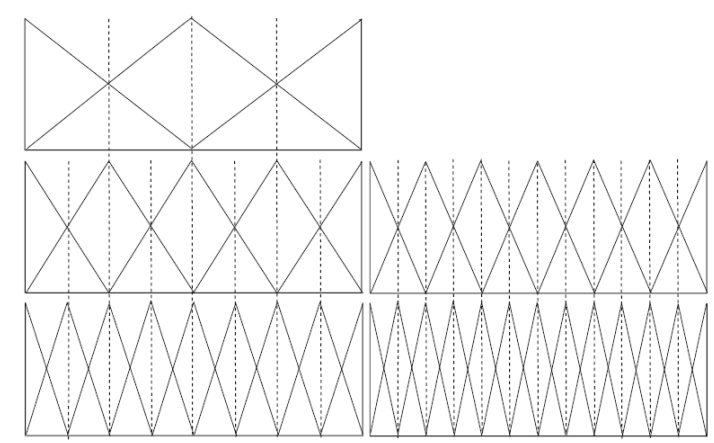

Figure 1: Linguistic hierarchies of 3, 5 and 9 labels and 7 and 13 labels

Figure 1 refers the hierachy of the linguistic domains as their triangular fuzzy representation. There is a limitation in the sets that can be used in LH since the level $t+1$ is generated from the following relation[16]:

$$
S^{n(t)} \rightarrow S^{n(2(n(t)-1)=n(t+1)}
$$

where $n(t)$ is the granularity of the linguistic term set.

The transformation function to translate linguistic term set with granularity $n(t)$ to a linguistic term set having granularity $n\left(t^{\prime}\right)$ is as follows. Eq. (4) defines the level that the $n(t)$ can be transformed. Then, $T F$ function calculates the 2-Tuple form of the new level.

$$
\begin{aligned}
& T F_{t^{\prime}}^{t}=\left(S_{i}^{n\left(t^{\prime}\right)}, \alpha^{n\left(t^{\prime}\right)}\right) \\
& =\Delta\left(\frac{\Delta^{-1}\left(\left(S_{i}^{n(t)}, \alpha^{n(t)}\right)\right) \times\left(n\left(t^{\prime}\right)-1\right)}{n(t)-1}\right)
\end{aligned}
$$

Transformation function enables the normalization of multi-granulated information under one form. In GDM, the other challenge is to aggregate all the point of views. To manage to combine different assessments of DMs, various aggregation operators are proposed in the literature [17], and they are widely used in decision-making field.

The following aggregation operator is Weighted Aggregation Operator (WAO). It has been chosen to be used in this study; WAO relation is computed as:

$$
\begin{array}{r}
\vec{x}=\left(\frac{\sum_{i=1}^{n} \Delta^{-1}\left(r_{i j}, \alpha_{i j}\right) \times \Delta^{-1}\left(w_{i}, \alpha_{i}\right)}{\sum_{i=1}^{n} \Delta^{-1}\left(w_{i}, \alpha_{i}\right)}\right) \\
=\Delta\left(\frac{\sum_{i=1}^{n} \beta_{i} \times w_{i}}{\sum_{i=0}^{n} w_{i}}\right)
\end{array}
$$

where $w_{i}$ values are the weights of DMs, $\beta_{i}$ values are the normalized assessments of each DM.
In the proposed methodology for strategy selection, the normalization process will be applied with Eq. (4) and Eq. (5), moreover, the aggregated final assessments will be obtained by Eq. (6).

The next section gives the detailed steps of the approach.

\section{Proposed Methodology}

The fundamental focus of this study is to select a suitable e-commerce strategy for an SME. The first step is to make an in-depth assessment of the internal and external factors of the company related to ecommerce. That evaluation helps to generate possible strategic alternatives for the company.

Furthermore, as a second step, the weighting of the selection criteria is very critical. The weights are the main guidelines to select the most appropriate strategy for the organization.

In the weighting procedure, GDM is suggested with multiple experts. Different granulated linguistic scales are proposed to each member of the group consistent with their degree of knowledge. The granularity of the linguistic scale augments as the level of knowledge increases[14].

The proposed techniques include the use of a software program called FLINTSTONES [11]. This program enables the rapid normalization and unification of 2Tuple linguistic variables by the same techniques given in Section 2. It also accelerates the decisionmaking process since the program drives all calculations.

Furthermore, the program enables to make linguistic decision making, to select the most suitable alternative.

Figure 2 summarizes the steps of the suggested procedure. The proposed process is a knowledge/expert-based system where the information provided for the system is coming from experienced decision makers about the subject. The reason to apply expert based system for a strategy selection subject is to accelerate the decision-making process and enable the participation of related decision makers to the decision-making procedure. Application of the implied technique for e-commerce strategy selection is given in the next section.

\subsection{Application: E-commerce Strategy Selection for SME}

To test the plausibility of the techniques, a case study is conducted for an SME who works in the textile industry.

The selected firm is a very young firm who manufacture its products without the participation of any other third-party firm. Its products are hand-made 
bags with unusual styles [18]. The SME sales its products via the internet and a design store where various designers sell their products.

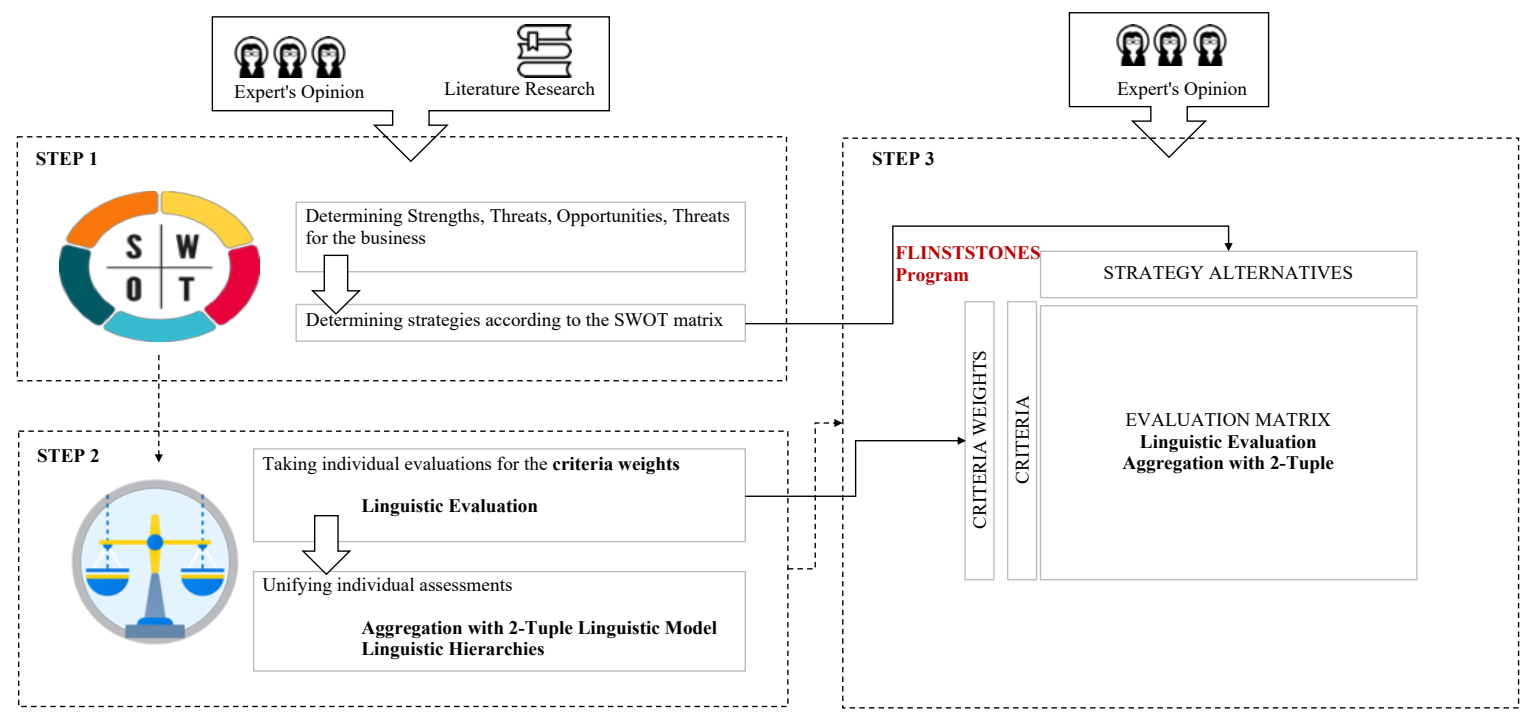

Figure 2. Basic steps of the proposed methodology

However, the company wants mostly to focus on their sales from e-store, and they want to generate a suitable e-commerce strategy for them to succeed in a competitive environment.

To be able to conduct a GDM, a decision-making group is formed from two owners of the company and an academician who works about strategic management subject. To start with, three different decision makers made an in-depth evaluation of the company together. Due to the knowledge difference, different linguistic scales have been assigned to DMs. Two owners of the company evaluated in $S^{3}$ (L-M-H), and the academician made the evaluations in $S^{5}$ (VL$\mathrm{L}-\mathrm{M}-\mathrm{H}-\mathrm{VH})$. Their linguistic sets are given in Figure 3.
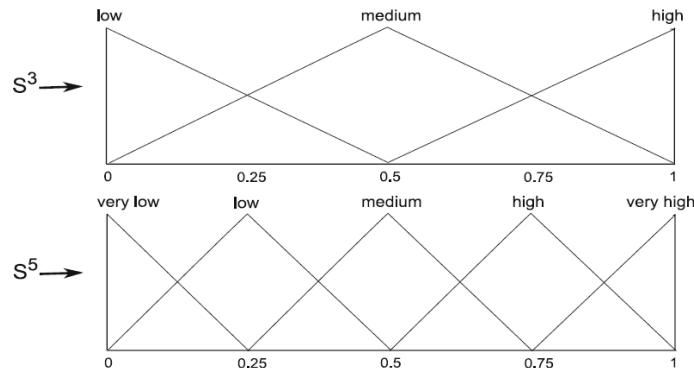

Figure 3: Linguistic sets provided to the experts

Step 1: The SWOT matrix is generated as in Table 3.

The strengths and weaknesses related to the internal organization and the opportunities and threats related to the external environment of the company are detected with the decision-making group.
Afterward, alternative strategies are assigned within the SWOT matrix. They are also presented in Table 3.

Step 2: Next process is the weighting of the selection criteria. In this methodology selection criteria are the ones detected in the SWOT matrix. So, it exists two levels of criteria where the first level consists of strengths, threats, opportunities, and weaknesses and the second level consists of their sub criteria detected in Table 2.

The first and the second level criteria importance assessed separately by DMs. Table 2 gives the linguistic evaluations of each expert and the aggregated 2-Tuple values for first level criteria. Then Table 4 gives the second level criteria importance. First Eq. (3) is used to translate linguistic values into the 2-Tuple form. Later Eq. (5) is applied to normalize and afterward Eq. (6) is applied to aggregate. The weight vector for Eq (6) is 0.275 for first and second expert and 0.45 for the third expert. The weights are assigned according to the granularity of the linguistic scales. All the linguistic sets are unified at second level $S^{5}$.

\begin{tabular}{|l|l|l|l|l|}
\hline CRITERIA & EX.1 & EX.2 & EX.3 & $\begin{array}{l}\text { AGG. } \\
\text { VALUES }\end{array}$ \\
\hline Strengths & M & H & M & $(\mathrm{VH}, 0)$ \\
Weaknesses & H & H & VH & $(\mathrm{H}, 0.45)$ \\
Opportunities & L & H & L & $(\mathrm{H},-0.44)$ \\
Threats & H & M & VH & $(\mathrm{M},-0.44)$ \\
\hline
\end{tabular}

Table 2: First level criteria importance in the 2-Tuple form 


\begin{tabular}{|c|c|c|}
\hline $\begin{array}{l}\text { External } \\
\text { Factors }\end{array}$ & $\begin{array}{l}\quad \text { Strengths (S) } \\
\text { S1: Design advantage } \\
\text { S11: Matchless design } \\
\text { S12: Design similarities with well-known } \\
\text { brands } \\
\text { S13: Foreign brand perception } \\
\text { S2: Marketing advantage } \\
\text { S21: Young group of publicity agent who } \\
\text { can use social platforms actively. } \\
\text { S22: The owner of the company is a } \\
\text { former e-commerce manager with job } \\
\text { experience in well-known organizations, } \\
\text { so he has critical business networks }\end{array}$ & $\begin{array}{l}\text { Weaknesses (W) } \\
\text { W1: Disadvantages of design } \\
\text { W11: The customers take a long time to get } \\
\text { used to the bags because they do not have a } \\
\text { custom design. } \\
\text { W2: Cost disadvantages } \\
\text { W21: High material cost } \\
\text { W22: High product prices }\end{array}$ \\
\hline $\begin{array}{l}\text { Opportunities(O) } \\
\text { O1: Consumer advantage } \\
\text { O11: Reaching a large number of consumers } \\
\text { O12: } 7 / 24 \text { open store } \\
\text { O2: Cost advantage } \\
\text { O21: Less cost for starting and managing } \\
\text { the company } \\
\text { O22: No need for physical company setups }\end{array}$ & $\begin{array}{l}\text { SO1 Strategy: Strengthen emphasizing the } \\
\text { uniqueness of the products in online } \\
\text { stores. } \\
\text { SO2 Strategy: Saving costs by using } \\
\text { ancient business networks for marketing }\end{array}$ & $\begin{array}{l}\text { WO1 Strategy: Strengthen the visual } \\
\text { publications in social media to habituate } \\
\text { customers to the unusual design. } \\
\text { WO2 Strategy: Creating a good quality } \\
\text { product perception by posting good visuals } \\
\text { of products in the online store to convince } \\
\text { customers to pay the price. }\end{array}$ \\
\hline \begin{tabular}{l}
\multicolumn{1}{c}{ Threats (T) } \\
T1: Disadvantages of cost \\
T11: Customer may choose another brand for \\
the same price \\
T2: Competitive disadvantage \\
T21: Disable of having special offer \\
campaigns \\
T22: Keeping product quality at a high level
\end{tabular} & $\begin{array}{l}\text { ST1(SO1) Strategy: Strengthen } \\
\text { emphasizing the uniqueness of the } \\
\text { products in online stores }\end{array}$ & $\begin{array}{l}\text { WT1(WO1) Strategy: Strengthen the visual } \\
\text { publications in social media to habituate } \\
\text { customers to the unusual design }\end{array}$ \\
\hline
\end{tabular}

Table 3: SWOT matrix for e-commerce strategy selection

\begin{tabular}{|l|l|r|r|l|r|}
\hline SC & AI. & $\#$ & SC & AI. & $\#$ \\
\hline S11 & $(\mathrm{VH}, 0)$ & 1 & $\mathbf{O 1 1}$ & $(\mathrm{M}, 0.1)$ & 5 \\
S12 & $(\mathrm{VH}, 0)$ & 1 & $\mathbf{O 1 2}$ & $(\mathrm{VL}, 0)$ & 8 \\
S13 & $(\mathrm{VH}, 0)$ & 1 & $\mathbf{O 2 1}$ & $(\mathrm{VL}, 0.45)$ & 7 \\
S21 & $(\mathrm{VH},-$ & 2 & $\mathbf{O 2 2}$ & $(\mathrm{M},-0.44)$ & 6 \\
& $0.44)$ & & & & \\
S22 & $(\mathrm{H}, 0.1)$ & 3 & T11 & $(\mathrm{VH}, 0)$ & 1 \\
W11 & $(\mathrm{VH},-$ & 2 & T21 & $(\mathrm{VH}, 0)$ & 1 \\
& $0.44)$ & & & & \\
W21 & $(\mathrm{VH},-$ & 2 & T22 & $(\mathrm{VH}, 0)$ & 1 \\
W22 & $(\mathrm{M}, 0.44)$ & & & & \\
\hline
\end{tabular}

Table 4: Second level criteria aggregated importance

$$
\text { values (2-Tuple) }
$$

In Table 4, SC columns refer to the sub-criteria, AL refers to aggregated linguistic values, and \# refers to the ranking of the sub-criteria.

Step 3: This step is the selection process. At this stage, 2-Tuple linguistic decision making is applied with FLINTSTONES program.
The figures of the interface of the software during the calculations are given in Figure 4 and 5.

Later the ultimate ranking of the strategy alternatives is presented in Table 5.

\begin{tabular}{|c|c|c|}
\hline STRATEGIES & EV. RESULT & RANK \\
\hline SO1 & (Medium, 0.35) & 2 \\
SO2 & (Medium, -0.35) & 4 \\
WO1 & (High, -0.42) & 1 \\
WO2 & (Medium, 0.28) & 3 \\
\hline
\end{tabular}

Table 5: Aggregated evaluation results of the alternatives

\subsection{Results and Discussion}

As mentioned before, the interface of the FLINTSTONES program is shown in Figure 4 and 5. In Figure 4, the primary step is shown in which the data is entered in the FLINTSTONES.

Section 1 in Figure 4 is the area for the experts' input. In this case we assigned three different experts with multiple evaluation domains $\left(S^{3}\right.$ and $\left.S^{5}\right)$ which are 
shown in Section 4. Section 2 and 3 are the sections in which the alternatives and the criteria are assigned respectively.

In Figure 5, the results are presented with graphical presentation. According to the comparison rules given in the preliminaries, the ranking of the alternative strategies is obtained. The aggregation of experts' opinion plus the aggregation of criteria is done with Weighted Mean Operation in FLINTSTONES.

According to the results, the most suitable ecommerce strategy is selected as "WO1" which is the "Strengthen the visual publications in social media to habituate customers to the unusual design."

The evaluation of the third expert for each alternative according to the criteria is shown in Table 6. It is given as an example for the assessments. As it is seen from Table 6, the strategy selected as the most suitable one is generally ranked high for the criteria, which have great importance.

\begin{tabular}{|l|l|l|l|l|l|l|l|l|l|}
\hline C\# & S1 & S2 & S3 & S4 & C\# & S1 & S2 & S3 & S4 \\
\hline C1 & H & VL & VH & VH & C9 & H & M & H & H \\
C2 & L & L & VH & VH & C10 & M & H & M & VH \\
C3 & VH & VL & M & VH & C11 & L & H & M & L \\
C4 & VH & VL & H & VH & C12 & L & L & L & VL \\
C5 & L & H & VL & L & C13 & H & M & VH & VH \\
C6 & H & M & VH & L & C14 & VH & L & VH & H \\
C7 & M & H & L & M & C15 & VH & L & H & VH \\
C8 & M & M & H & VL & & & & & \\
\hline
\end{tabular}

Table 6: Evaluation of third expert as an example

This result shows that the weightinig is crucial for an healthy strategy selection since the weights have direct and essential impacts on the suitable solution.

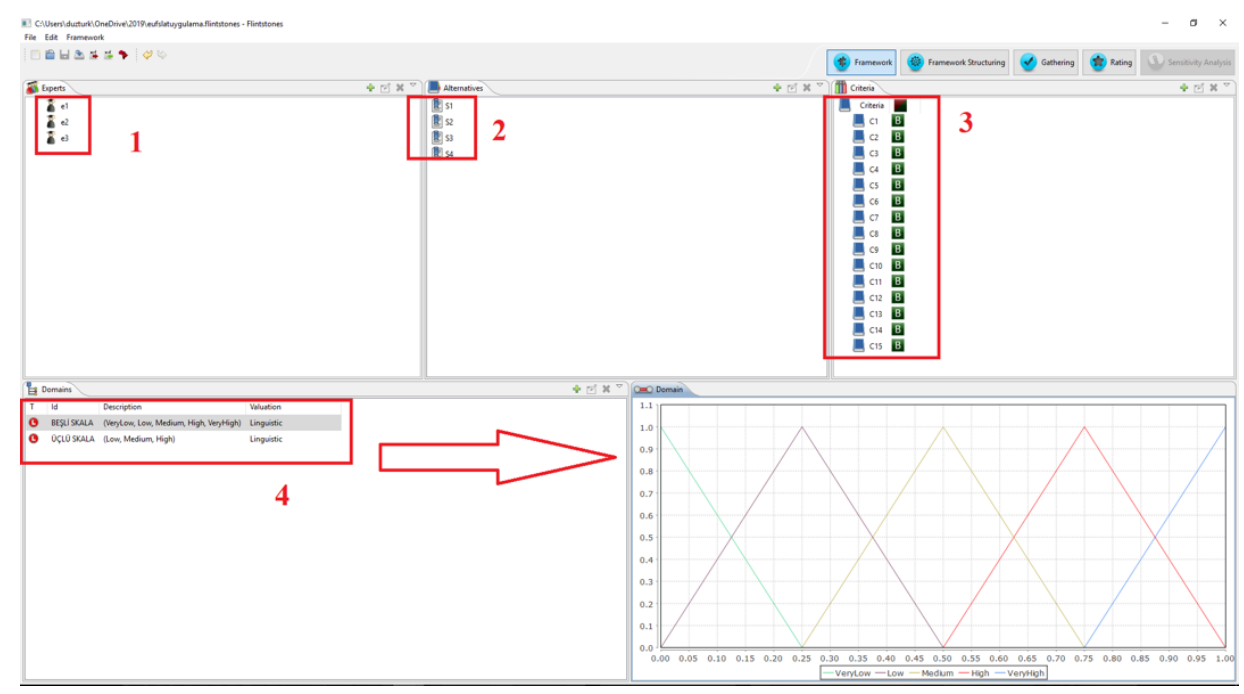

Figure 4: First step as entering the data into the program

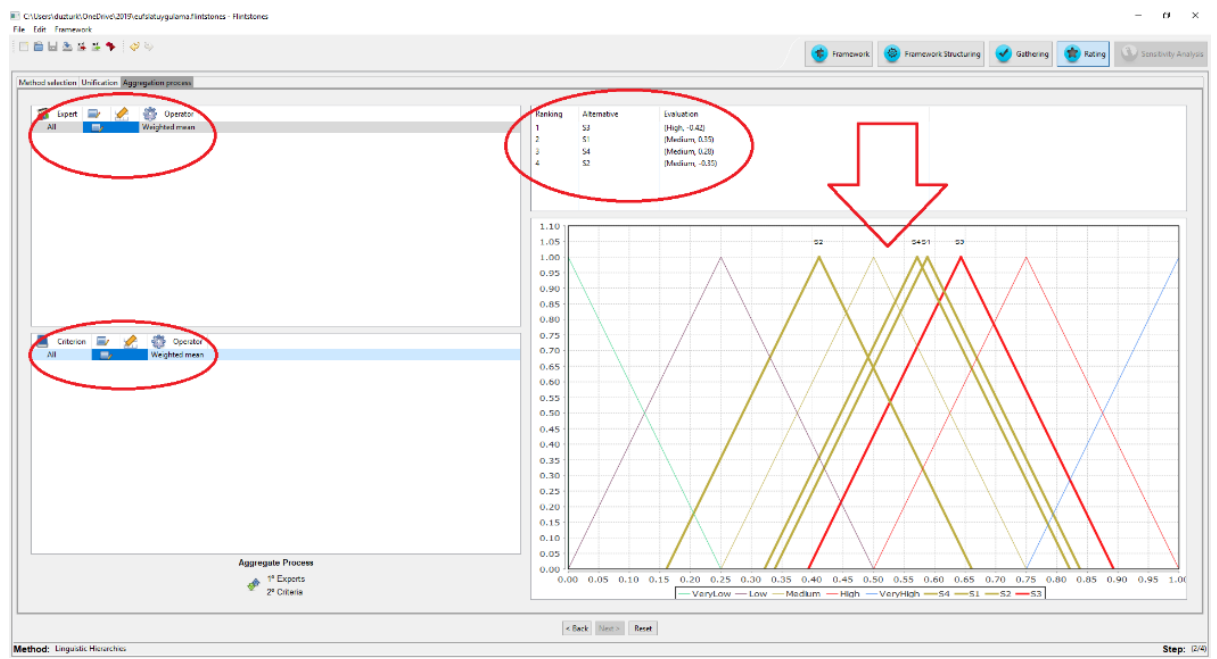

Figure 5: Last step: obtaining the ranking in the program 


\section{Conclusion and Perspectives}

Today, with the high rate of growth in mobile technologies, the proportion of e-commerce in our lives has started to expand. Almost every company, try to get a good pie in the e-commerce sector; therefore, new strategies are generated to obtain a competitive advantage.

To be able to obtain and hold a competitive advantage, the organization should know itself and its environment (customers, rivals, sector) in details. Motivated by this need, this study proposes a group decision-making methodology for a strategy selection, in which a powerful self-evaluation tool, SWOT, is suggested.

This strategy selection methodology consists of three different stages where the first one is composed of linguistic GDM integrated SWOT analysis, the second step contains the weighting of the strategy selection criteria, and the last step is the ranking of the criteria.

In the last step, a software program called FLINTSTONES is selected to use to accelerate the decision-making process. This software enables us to make calculations and selections with multi-granular linguistic data. The main reason that we have proposed a software program to the selection methodology is to speed up and facilitate the decision-making process. Moreover, the program is accessible through the internet [19], and it can be used by any organization.

To test the applicability of the suggested methodology, it is applied to an SME in the textile sector from Turkey. Two owners of the company and a one e-commerce expert are assigned as a decision-making group. The proposed steps are applied, and the results are collected.

The critical importance of the implied methodology is its rapidness through calculations and its flexible and comfortable assessment environments to its DMs. With these advantages, the techniques proposed an objective, robust and flexible selection approach for e-commerce strategy.

For further studies, this technique can be developed with larger granulated linguistic sets and different aggregation techniques to combine the criteria and the expert's opinion. Furthermore, instead of using linguistic decision making, different multi-criteria decision making tools can be applied to compare the results.

\section{Acknowledgment}

We are very grateful to work with the experts in this case. We want to thank for their efforts to support our study. This work is financially supported by Galatasaray University Research Fund.

\section{References}

[1] K. C. Laudon and C. G. Traver, E-commerce 2017: business, technology, society, Thirteenth Edition. Boston: Pearson, 2017.

[2] J. Allen et al., "Understanding the impact of ecommerce on last-mile light goods vehicle activity in urban areas: The case of London," Transp. Res. Part-Transp. Environ., vol. 61, pp. 325-338, Jun. 2018.

[3] E-commerce 2016: Business, Technology, Society. Pearson College Div, 2016.

[4] A. Baykasoglu and I. Golcuk, "Development of a novel multiple-attribute decision making model via fuzzy cognitive maps and hierarchical fuzzy TOPSIS," Inf. Sci., vol. 301, pp. 75-98, Apr. 2015.

[5] L. Yixiang and G. Jin, Research on Strategy Selection for the Development of "To Exercise" APP in Universities of Hubei Province. Wuhan: Wuhan Univ Technology Press, 2016.

[6] J. K. Khatri and B. Metri, "SWOT-AHP Approach for Sustainable Manufacturing Strategy Selection: A Case of Indian SME," Glob. Bus. Rev., vol. 17, no. 5, pp. 1211-1226, Oct. 2016.

[7] M. Beheshti, H. A. Mandiraji, and E. K. Zavadskas, "Strategy Portfolio Optimisation: A Copras GModm Hybrid Approach," Transform. Bus. Econ., vol. 15 , no. 3C, pp. 500-519, 2016.

[8] A. Baykasoglu and I. Golcuk, "Development of an interval type-2 fuzzy sets based hierarchical MADM model by combining DEMATEL and TOPSIS," Expert Syst. Appl., vol. 70, pp. 37-51, Mar. 2017.

[9] L. Sanny, B. H. Simamora, J. R. Polla, and J. L. Atipa, "Business Strategy Selection Using SWOT Analysis with ANP and Fuzzy TOPSIS for Improving Competitive Advantage," Pertanika J. Soc. Sci. Humanit., vol. 26, no. 2, pp. 1143-1158, Jun. 2018.

[10] H. Dincer, O. O. Akdeniz, and U. Hacioglu, "Competitive strategy selection in the European banking sector using a hybrid decision-making approach," Zb. Rad. Ekon. Fak. U Rijeci-Proc. Rij. Fac. Econ., vol. 36, no. 1, pp. 213-242, 2018.

[11] F. J. Estrella, M. Espinilla, F. Herrera, and L. Martínez, "FLINTSTONES: A fuzzy linguistic decision tools enhancement suite based on the 2tuple linguistic model and extensions," Inf. Sci., vol. 280, pp. 152-170, Oct. 2014.

[12] F. Herrera and L. Martinez, "A 2-tuple fuzzy linguistic representation model for computing with words," IEEE Trans. Fuzzy Syst., vol. 8, no. 6, pp. 746-752, Dec. 2000.

[13] F. Herrera and L. Martínez, “A 2-tuple fuzzy linguistic representation model for computing with 
words," IEEE Trans. Fuzzy Syst., vol. 8, no. 6, pp. 746-752, 2000.

[14] L. Martínez, R. M. Rodriguez, and F. Herrera, The 2-tuple Linguistic Model. Cham: Springer International Publishing, 2015.

[15] D. Black, "On the Rationale of Group Decisionmaking," J. Polit. Econ., vol. 56, no. 1, pp. 23-34, Feb. 1948.

[16] L. Martínez, J. Liu, J.-B. Yang, and F. Herrera, “A multigranular hierarchical linguistic model for design evaluation based on safety and cost analysis," Int. J. Intell. Syst., vol. 20, no. 12, pp. 1161-1194, 2005.
[17] S.-P. Wan, "2-Tuple Linguistic Hybrid Arithmetic Aggregation Operators and Application to Multiattribute Group Decision Making," Know-Based Syst, vol. 45, pp. 31-40, Jun. 2013.

[18] "Unusual Store," UnusualStore. [Online]. Available: https://www.unusualstore.net. [Accessed: 01-Mar-2019].

[19] "Bienvenido a FLINTSTONES | FLINTSTONES." [Online]. Available: https://sinbad2.ujaen.es/flintstones/?q=software. [Accessed: 04-Mar-2019]. 